\title{
Shorter lunch breaks lead secondary-school students to make less healthy dietary choices: multilevel analysis of cross-sectional national survey data
}

\author{
Nicholas Townsend* \\ Nuffield Department of Population Health, University of Oxford, British Heart Foundation Centre on Population \\ Approaches for Non-Communicable Disease Prevention, Old Road Campus, Headington, Oxford OX3 7LF, UK
}

Submitted 10 September 2013: Final revision received 20 May 2014: Accepted 13 July 2014: First published online 5 September 2014

\begin{abstract}
Objective: At the time of the study a number of schools within Wales had shortened the amount of time they allow for lunch break. The study investigated the association between length of lunch break and the dietary choices of students in secondary schools.

Design: Student-level data, collected through anonymised questionnaires, included reported dietary choices and correlates of these; data on school approaches to food were collected through postal surveys. Multilevel analysis was used to study the independent association between lunch-break length and student dietary choice.

Setting: Data were collected from secondary schools in Wales that were part of the 2005/2006 Health Behaviour in School-aged Children (HBSC) study.

Subjects: The final sample for analysis included data from 6693 students aged 11-16 years and 289 teachers from sixty-four secondary schools in Wales.

Results: Once controlling for many individual-level and school-level factors, the length of time allowed for lunch across the range for schools included in the study ( minimum $=25 \mathrm{~min}$, maximum $=62.5 \mathrm{~min}$ ) was associated with higher odds of students eating fruit for lunch $(2 \cdot 20 ; 95 \%$ CI $1 \cdot 18,4 \cdot 11)$ and fruit and vegetables on a daily basis $(2 \cdot 15 ; 95 \%$ CI $1 \cdot 33,3 \cdot 47)$ but lower odds of eating unhealthy foods on a daily basis (0.44; $95 \%$ CI $0 \cdot 24,0 \cdot 80)$.

Conclusions: Shorter lunch breaks are associated with less healthy dietary choices by students. Schools should consider the impact that lunch-break length has on student dietary choice as well as on other behaviours. Policy makers should work with schools in encouraging them to maintain lunch breaks of a length that allow pupils to make healthy choices.
\end{abstract}

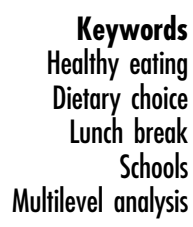

Improving the diet of children is a policy priority in the UK, given impetus by the concern over the growing prevalence of child obesity ${ }^{(1-5)}$ which has been predicted to continue $^{(6)}$. Schools are a popular setting in which to promote healthy eating as they provide unparalleled access to children ${ }^{(7,8)}$ who spend more time in schools than in any other environment outside the home ${ }^{(7,9)}$. This has been recognised by policy makers within the UK through a consistent focus on the food served in schools, culminating in the School Food Report commissioned in 2012 by the UK Department of Education and published in $2013^{(10)}$.

There is no consensus, however, on the impact of schools on the dietary choices of students, with a number of multilevel studies finding no significant school-level variance in student dietary choice once controlling for student-level characteristics ${ }^{(11-14)}$. These suggest that differences in student dietary choice between schools are due to the composition of the individuals who attend the schools and not the school approaches to food. A recent multilevel study that had access to a greater number of schools and students, however, did find a school effect in student dietary behaviour once controlling for a large number of individual-level characteristics ${ }^{(15)}$. Findings from the latter study suggest that students in schools that had more actions in place to promote healthy eating were more likely to eat fruit and vegetables ${ }^{(15)}$.

This finding provides support for the multifactorial whole-school approach to the promotion of healthy eating, developed in light of the failure of school-based 
healthy eating brief interventions, which often consisted solely of an educational component ${ }^{(16)}$, to produce significant changes in behaviour ${ }^{(8,17-19)}$. A whole-school approach recognises healthy eating as a complex behaviour determined by influences at multiple levels. No single approach towards promoting a healthy diet is therefore likely to be successful on its own. A wholeschool approach is implemented through the 'settings'based health-promoting school concept ${ }^{(20)}$, which is developed from the application of a socio-ecological model to health, as advocated by the Ottawa Charter for Health Promotion ${ }^{(21)}$. Such multi-component interventions, based on a socio-ecological model, have been found to be effective in changing the dietary behaviour of students ${ }^{(16)}$. A whole-school approach is one in which the health education curriculum is reinforced by other aspects of the school including policies, culture, environment, engagement with families and the wider community and availability of healthy foods such as fresh fruit and vegetables, promoting healthy dietary choice through multiple synergistic actions ${ }^{(15)}$. This approach has gained much support from policy makers, with all UK national governments recommending a whole-school approach to healthy eating ${ }^{(22-26)}$. Additionally the WHO recommends the use of whole-school multi-component interventions, which include teaching in the curriculum, parental involvement, supportive environments and a healthy food service $^{(27)}$.

An important aspect of a while-school approach to healthy eating includes not only the food available within the school, but also the regulations and environment in which this food is available. Students can be discouraged from eating in school due to poor dining facilities, poor food, long queues and short lunch breaks ${ }^{(28,29)}$, leading them to purchase lunch from competing local outlets such as chip shops, fast-food vans, shops and restaurants $^{(8,30,31)}$. Lunch arrangements in secondary schools in Wales follow those found throughout the UK. Meals are generally served as a canteen-style lunch service with a cash cafeteria service offered from one or more outlets, although students may bring food from home ${ }^{(30,32)}$. About $45 \%$ of students use the school meal service, which is most commonly provided by the Local Education Authority's in-house service, although some schools may use private contractors ${ }^{(30,32)}$. The next most popular option after a school lunch is for students to bring a packed lunch to school, with a small number of schools providing a packed lunch only option, although this is rare in secondary schools ${ }^{(15,32)}$. In addition to school meals and packed lunches, some students may buy a snack from school outlets including at morning break, some may leave during lunch break to buy food from outlets off the school grounds, while others return home for lunch, although this final option has been found to be less common $^{(15)}$. The lunch break also doubles as an afternoon break and students are expected to return for lessons after this. In schools with short lunch breaks students are less likely to eat a school meal; instead they may take part in social activities, leave the school grounds to buy foods, buy lunch at morning break time or choose to bring in a packed lunch ${ }^{(33)}$. It has been found that few packed lunches meet the school meal standards, with only about half of them found to contain a serving of fruit, less than one-fifth containing a serving of vegetables, more than $80 \%$ including a restricted snack, such as crisps or confectionery, and over $60 \%$ containing a sweetened $\operatorname{drink}^{(34)}$.

Although no papers were identified by the author that studied the impact of lunch-break length on student dietary choice, qualitative aspects of reports on school approaches to food suggest that the amount of time allowed for lunch does affect what students choose to eat $^{(30,33)}$, with students in secondary schools with a lunch time of $45 \mathrm{~min}$ or less reporting to be less likely to eat a meal $^{(33)}$, which has been shown to be associated with poorer food choices and lower levels of energy and nutrient intake at lunchtime ${ }^{(35)}$. Great variation has been found between schools in the UK in the length of time they allow for lunch ${ }^{(8,33)}$, with many schools in Wales introducing shorter lunch breaks, some as short as $30 \mathrm{~min}$, under the motivation of improving student behaviour ${ }^{(30)}$. This is particularly concerning as data from the 2009/2010 Health Behaviour in School-aged Children (HBSC) study suggest that students in Wales eat less fruit than average for the forty-one countries sampled in the study and that school approaches are important in promoting healthy eating among this age group ${ }^{(36)}$.

The current paper presents findings from a multilevel analysis of the length of lunch break and the dietary behaviour of students, adjusting for a number of studentand school-level confounding variables. These variables include those found at the individual level, to allow for differences in the composition of students within the schools to be controlled for, along with the school-level actions to promote healthy eating that have been found to be associated with dietary choice ${ }^{(15,37)}$, such that the independent association between lunch-break length and student dietary choice can be studied.

\section{Methods}

\section{Student-level data}

Data on the dietary behaviour of secondary-school students aged 11-16 years and student-level confounding variables were collected through the Wales sample of the HBSC study ${ }^{(38)}$. Sampling and data collection protocol for the 2005/2006 HBSC followed that for the 2001/2002 survey $^{(38,39)}$.

The student survey was administered between January and April 2006, as a self-completion in-school questionnaire to all sampled students attending school on the 
day of the survey; absent students were not followed up. All students were informed that participation was voluntary and provided with individual unmarked envelopes in which to seal their questionnaires.

\section{Dependent variables}

Two types of self-report dietary behaviour measure were used as dependent variables: (i) summary measures of the frequency of consumption of fruit and vegetables and unhealthy food items; and (ii) measures of whether or not three different foods were eaten at lunchtime.

For the frequency measures, students were asked: 'How many times a week do you usually eat...?' for fruit and vegetables and four different unhealthy food items (cola and other soft drinks; sweets and chocolate; crisps; chips). For each food item, there were seven possible responses ('never', 'less than once a week', 'once a week', '2-4 days a week', '5-6 days a week', 'once a day every day' and 'every day more than once'). Each of the two summary measures was obtained by counting, for each student, whether fruit or vegetables (0-2) or the unhealthy (0-4) items were reported as consumed at least daily. The daily intake variables came from the selected 'method of choice' for the HBSC survey. This an FFQ that has been developed and validated to be used as the primary tool for collecting dietary information from participants in all HBSC countries ${ }^{(39)}$.

For the foods eaten at lunchtime, dichotomous variables were derived to indicate those students who agreed (1) or disagreed (0) that they ate the food for lunch. This was based on responses to questions which asked students to indicate their agreement with the statement: 'I eat (food) for lunch' asked for three food items (fruit; chips; sweets and chocolate) on a seven-point scale. Those indicating that they 'agree very strongly', 'agree strongly' or 'agree slightly' were coded as agreeing that they ate that food item for lunch. These questions were taken from a study on adolescent food choice ${ }^{(40)}$. They were included in the present study to provide a measure of student lunch choices since it was hypothesised that lunch behaviour may be more strongly associated with school actions than food frequencies over the week.

\section{Independent variables}

In order that the association between lunch-break length and healthy dietary choice could be investigated while adjusting for the composition of students within the schools, a number of student-level independent variables identified in the literature and case studies and that have been included in previous analyses of these data ${ }^{(15,37)}$ were controlled for in the final analyses.

\section{School-level data}

School-level data were collected through postal questionnaires sent to teachers within schools in which the
HBSC study was carried out, alongside information provided by the Welsh Government.

These teacher questionnaires collected data on school approaches to healthy eating including: education about a healthy diet, healthy eating policy, healthy eating schemes, the provision of food and the food environment. The majority of school-level variables came from precoded close-ended questions that provided variable categories as responses $^{(15,37)}$.

Although a more recent HBSC survey has been completed $^{(36)}$, surveys were sent to school staff during the 2005/06 academic year, at the same time that the HBSC survey was being administered to students, so that a contemporary analysis of school and student data could be completed. Data collection from schools aimed to achieve two or more completed questionnaires from each school, allowing modal responses of teachers within the school to be used in the derivation of variables. Questionnaires were sent to eight teachers within each school. It was hoped to randomly select individual teachers from teacher lists; however, as only fourteen schools agreed to provide teacher lists this was not possible and in the remaining fifty-six schools contacts within the school distributed questionnaires. Instructions were provided for these contacts on how to select teachers to complete the survey. They were advised that this should include one member of the management team (head teacher/deputy head), the teacher responsible for the School Nutrition Action Group and the head of Personal, Social Education; these staff were identified as being the most appropriate to receive the questionnaire through discussions with the schools themselves. School Nutrition Action Groups are schoolbased alliances in which staff, pupils and caterers, often supported by health and education professionals, work together to increase the uptake of a healthier diet and ensure consistent messages from the curriculum and the food service. It was then advised that a random selection of five other teachers should receive the survey. However, in schools in which staff lists were not provided and contacts distributed surveys the author could not guarantee that this was truly random. No significant differences were found between schools in the number or types of staff returning questionnaires and the means by which the staff surveys were distributed.

\section{Lunch-break length variable}

A variable on the amount of time in minutes schools allow for lunch was derived from the teacher postal questionnaires. For the analysis the lunch-break length variable was standardised using $0-1$ scaling. This was done by recalculating each data point by subtracting the shortest lunch-break length and dividing by the difference between the longest lunch-break length and the shortest. This means the range is now 0 to 1 rather than $25 \mathrm{~min}$ to $62.5 \mathrm{~min}$. Although all data points were still included in the analysis, odds ratios were calculated that can be 
interpreted as the increase in odds of the outcome associated with being in the school with the longest lunch break compared with the odds of the outcome being in the school with the shortest lunch break, rather than for every 1-min increase in lunch-break length.

\section{Independent variables}

School-level variables were included in the analysis as they were characteristics identified in the literature or case studies that influence student dietary choice. Some variables were included as they were used in HBSC sampling. These variables included the healthy-eating-promoting actions schools had in place and fixed school characteristics that schools could not influence. Previous studies found a significant association between the number of these healthy-eating-promoting actions schools have in place and student dietary choice ${ }^{(15)}$ and studied the varying impact of these variables as part of a socioecological model on the promotion of healthy eating in schools $^{(37)}$. It was therefore important to control for these variables to allow for an independent association of lunchbreak length to be studied, even though there was no significant association between the length of time schools allowed for lunch and the number of other healthy-eatingpromoting actions they had in place.

Healthy-eating-promoting actions. All variables included as healthy-eating-promoting actions came from the teacher survey, except for information on school involvement in the Welsh Network of Healthy School Schemes (WNHSS) that was provided by the Welsh Government. The WNHSS encourages the development of health-promoting schools in Wales. Schools involved in health-promoting school networks have been found to make significant moves towards developing a whole-school approach to food and nutrition ${ }^{(41)}$. Within the WNHSS, schools complete phases in which they implement a number of health-promoting actions. Although healthy eating promotion is not compulsory within the WNHSS many schools choose this as an area to improve, with funding made available for schools in the WNHSS to develop food and fitness projects in $2006^{(42)}$, after data collection for the present study had been completed. Once schools are adjudged to have completed one phase, through inspection by outside parties, they move on to the next ${ }^{(43)}$.

Fixed school characteristics. Fixed school characteristics were school-level factors that the school could not influence and were not healthy-eating-promoting actions. The Welsh Government provided information on three fixed school characteristics considered in the sampling framework of the HBSC survey: (i) school type (state (publicly funded); independent (fee paying)); (ii) number of students in the school in Years 7-11; and (iii) percentage of students eligible for free school meals. It was important to control for these characteristics as they were found to be associated with the number of actions schools had in place. Independent schools had more actions in place than state schools; an inverse relationship was found between the percentage of students in the school eligible for free school meals and the number of actions; while an inverted-U relationship was found with school size, with the smallest and largest schools having the most number of actions in place. The fourth fixed school characteristic, whether there was a shop close to the school from which students could buy food, came from the teacher survey, and was asked directly of staff.

\section{Data analysis}

Two-level random effects models were run in MlWin 2.1 for each dependent variable. These were logistic for the binary lunch variables and ordinal logistic for the frequency variables. From these models the association between length of school lunch break and each of the dependent variables was calculated while controlling for all school-level covariates and student-level covariates. This allows us to investigate the association between the amount of time allowed for lunch in school and the dietary choice of students while controlling for confounding factors at both the school and student level.

Any individual case with any variable missing was excluded before analysis so that results for each of these models could be comparable.

\section{Results}

In the final sample seventy schools completed the HBSC survey, with 7300 students completing the questionnaire. Information was not always available on pupil nonattendance on the day that fieldwork took place, meaning that pupil-level response rates have to be approximated. These are estimated to be over $70 \%$ in most HBSC countries $^{(44)}$ while an estimated 9150 students in the original Welsh sample results in a response rate of close to $80 \%$ for the present study. Only sixty-four schools completed two or more teacher questionnaires (total $n 289$, response rate $=52 \%)$ and thus school and student data from these schools only could be included in the analysis. This resulted in a final sample for the analysis of 6693 students in sixtyfour schools in Wales. Data from all these schools were used in the final analyses although missing data on an individual level resulted in sample sizes of 4998 to 4858 used in the final regression models; this equated to $75.7 \%$ to $72.6 \%$ of students who completed surveys within these schools.

All schools that did not return two or more questionnaires were state schools. This resulted in $90 \%$ of the state schools from the HBSC sample being retained for the analysis, equating to $26 \%$ of the state schools in Wales. There were no significant differences between schools that did and did not return two or more questionnaires in terms of location, language medium of the school, number of students in the school or the proportion of students eligible for free school meals. 


\section{Dependent variables}

Of students, $54 \cdot 1 \%$ reported that they ate neither fruit nor vegetables on a daily basis and $20.3 \%$ reported to eat both daily; $51.9 \%$ of students reported that they ate none of the unhealthy foods on a daily basis while $3.7 \%$ reported to eat all of them daily. About half (50.5\%) of the students agreed that they ate fruit for lunch, $26 \cdot 3 \%$ agreed that they ate chips and $36.9 \%$ agreed that they ate sweets (Table 1 ).

\section{Independent variables}

\section{Student-level variables}

Table 2 displays the student-level independent variables included in the analysis, the value for each variable and the percentage of responses from students. All studentlevel variables were included in the final models.

\section{School-level variables}

Table 3 displays the school-level independent variables included in the analysis. This includes the healthy-eatingpromoting actions and the fixed school characteristics that were controlled for. Table 3 also displays the values for each variable and the modal responses from schools.

\section{Multilevel analysis of length of lunch break}

The mean lunch-break length for schools in our sample was $48.3 \mathrm{~min}$, with a maximum of $62.5 \mathrm{~min}$ and a minimum of $25 \mathrm{~min}$.

Cross-tabulations of dependent variables against schools stratified by mean lunch-break length indicated that in schools with a lunch break longer than the mean, a greater percentage of students reported to eat fruit for lunch and a lower percentage reported to eat chips and

Table 1 Percentage of pupil responses for dependent variables; secondary schools in Wales that were part of the 2005/2006 Health Behaviour in School-aged Children (HBSC) study

\begin{tabular}{lr}
\hline Daily intake frequency variables & $\%$ \\
\hline Healthy sum score ( $n$ 6606) & $54 \cdot 1$ \\
Eat neither fruit nor vegetables on a daily basis & 25.6 \\
Eat either fruit or vegetables on a daily basis & 20.3 \\
Eat both fruit and vegetables on a daily basis & \\
Unhealthy sum score ( $n$ 6447) & 51.9 \\
Eat none of the unhealthy foods on a daily basis & 23.4 \\
Eat 1 of the unhealthy foods on a daily basis & 13.4 \\
Eat 2 of the unhealthy foods on a daily basis & $7 \cdot 6$ \\
Eat 3 of the unhealthy foods on a daily basis & 3.7 \\
Eat 4 of the unhealthy foods on a daily basis & \\
I eat for lunch variables & 50.5 \\
Eat fruit for lunch ( $n$ 6097) & 49.5 \\
$\quad$ Agree & \\
Do not agree & 26.3 \\
Eat chips for lunch ( $n$ 6061) & 73.7 \\
$\quad$ Agree & \\
Do not agree & 36.9 \\
Eat sweets for lunch ( $n$ 6054) & 63.1 \\
$\quad$ Agree &
\end{tabular}

sweets, in comparison to schools with a lunch-break length shorter than the mean. Students in these schools also reported a higher mean score for fruit and vegetable daily intake and a lower mean for daily intake of the unhealthy foods (Table 4).

In final models, students in schools with a longer lunch break had significantly higher odds of eating fruit for lunch and fruit and vegetables on a daily basis than students in schools with a shorter lunch break. They also had significantly lower odds of eating unhealthy foods on a daily basis. Odds for students reporting to eat chips for lunch and sweets for lunch were not significantly associated with the length of lunch break in the school (Table 5).

\section{Discussion}

Findings from the present study indicate that longer lunch breaks in schools were associated with greater odds of students agreeing that they ate fruit for lunch and reporting to eat fruit or vegetables on a daily basis. They also had lower odds of reporting to eat one of the unhealthy foods on a daily basis. By using multilevel modelling we were able to separate determinants operating at the individual level from those operating at the school level and to control for factors that may influence dietary choice.

The main weakness of the study is that most of the variables come from self-report questionnaires. Both sets of dependent variables were derived from self-reported questions in the HBSC student survey. The daily intake variables came from the selected 'method of choice' for the HBSC survey that has been validated ${ }^{(39)}$ while the lunch variables came from questions asking about the choice of specific foods for lunch ${ }^{(40)}$. Although these lunch variables came from a paper published in 1995, leading to concerns of applicability to the reporting of current adolescent lunch behaviour, these were examined in case studies prior to the data collection. The student-level independent variables all came from the HBSC survey and were self-reported. Many of the school-level variables are crude, unvalidated measures which are dependent upon teacher responses and provide no measure of quality for these actions. For both student-level and school-level variables unless there is substantial variation across schools in reporting bias, this should not affect the estimated association in the models. The data for the present study are cross-sectional; as the study is not longitudinal no causality can be inferred, only a significant association derived.

Despite these limitations the HBSC study remains a large-scale survey providing nationally representative data from a large number of schools and pupils in Wales, with very limited data available elsewhere for studies of this nature. These findings agree with past qualitative studies ${ }^{(28-30,33)}$ that have found students were noticeably more likely to make unhealthy food choices in schools 
Table 2 Independent student-level variables against percentage of pupil responses; secondary schools in Wales that were part of the 2005/2006 Health Behaviour in School-aged Children (HBSC) study

\begin{tabular}{|c|c|c|c|}
\hline Pupil-level variable & $\%$ & Pupil-level variable & $\%$ \\
\hline \multicolumn{2}{|l|}{ Gender ( $n$ 6688) } & \multicolumn{2}{|l|}{ On diet $(n 6650)$} \\
\hline Boy & $49 \cdot 7$ & Yes & $20 \cdot 1$ \\
\hline Girl & $50 \cdot 3$ & No & 79.9 \\
\hline \multicolumn{2}{|l|}{ Year group ( $n$ 6693) } & \multicolumn{2}{|c|}{ No. of subjects useful in learning on healthy eating ( $n$ 6291) } \\
\hline Year 7 & $21 \cdot 1$ & 0 subjects & 2.4 \\
\hline Year 8 & $19 \cdot 4$ & 1 subject & $7 \cdot 6$ \\
\hline Year 9 & $21 \cdot 0$ & 2 subjects & $18 \cdot 1$ \\
\hline Year 10 & $19 \cdot 8$ & 3 subjects & $32 \cdot 1$ \\
\hline Year 11 & $18 \cdot 7$ & 4 subjects & 39.8 \\
\hline \multicolumn{2}{|l|}{ Family set up ( $n$ 6693) } & \multicolumn{2}{|c|}{ Family Affluence Scale* ( $n$ 6337) } \\
\hline Both parents & $64 \cdot 2$ & Low & 4.7 \\
\hline Step family & $11 \cdot 6$ & Medium & $42 \cdot 6$ \\
\hline Single parent & $24 \cdot 1$ & High & $52 \cdot 7$ \\
\hline \multicolumn{2}{|l|}{ TV viewing per day ( $n$ 6693) } & \multicolumn{2}{|c|}{ Engagement with school† ( $n$ 5912) } \\
\hline Min hours & 0.0 & 0 & 0.7 \\
\hline Max hours & $7 \cdot 0$ & 1 & $7 \cdot 1$ \\
\hline Mean hours & $2 \cdot 68$ & $\begin{array}{l}2 \\
3\end{array}$ & $\begin{array}{l}31 \cdot 8 \\
60 \cdot 5\end{array}$ \\
\hline \multicolumn{2}{|c|}{ No. of days have breakfast ( $n$ 6426) } & \multicolumn{2}{|c|}{ No. of evenings spend time with friends ( $n 6426$ ) } \\
\hline Never have breakfast & 4.9 & Never & 13.4 \\
\hline $1 \mathrm{~d}$ & $6 \cdot 3$ & 1 evening & $12 \cdot 3$ \\
\hline $2 d$ & $10 \cdot 0$ & 2 evenings & $15 \cdot 5$ \\
\hline $3 d$ & 4.5 & 3 evenings & $15 \cdot 1$ \\
\hline $4 d$ & $6 \cdot 1$ & 4 evenings & $10 \cdot 7$ \\
\hline $5 d$ & $9 \cdot 3$ & 5 evenings & $11 \cdot 1$ \\
\hline $6 \mathrm{~d}$ & $10 \cdot 1$ & 6 evenings & 8.4 \\
\hline $7 d$ & 48.9 & 7 evenings & 13.5 \\
\hline \multicolumn{2}{|c|}{ No. of days spend time after school with friends ( $n$ 6379) } & \multicolumn{2}{|l|}{ School lunch behaviour ( $n$ 6478) } \\
\hline Never & 11.6 & Eat a school dinner & 39.7 \\
\hline $1 \mathrm{~d}$ & 11.0 & Buy a snack at school & $10 \cdot 6$ \\
\hline $2 d$ & $16 \cdot 2$ & Eat a packed lunch & 27.5 \\
\hline $3 d$ & 20.7 & Buy lunch outside & 13.6 \\
\hline $4 d$ & $10 \cdot 8$ & Go to a home for lunch & $2 \cdot 8$ \\
\hline $5 d$ & 29.7 & Don't have lunch & $5 \cdot 8$ \\
\hline \multicolumn{2}{|c|}{ Health conscious $\ddagger$ ( $n$ 6135), ICC $=0.016$} & \multicolumn{2}{|c|}{ Conscious healthy eating $\neq(n 6120), I C C=0.015$} \\
\hline Agree very strongly & $10 \cdot 3$ & Agree very strongly & $11 \cdot 1$ \\
\hline Agree strongly & $17 \cdot 7$ & Agree strongly & $17 \cdot 9$ \\
\hline Agree slightly & $24 \cdot 3$ & Agree slightly & $25 \cdot 9$ \\
\hline Neither agree nor disagree & 23.9 & Neither agree nor disagree & $25 \cdot 1$ \\
\hline Disagree slightly & $11 \cdot 3$ & Disagree slightly & $9 \cdot 3$ \\
\hline Disagree strongly & 5.4 & Disagree strongly & 4.4 \\
\hline Disagree very strongly & $7 \cdot 0$ & Disagree very strongly & $6 \cdot 3$ \\
\hline
\end{tabular}

TV, television; ICC, intra-class correlation coefficient.

*Family Affluence Scale is a four-item composite score to judge individual socio-economic status.

†Engagement with school variable is a four-level composite variable derived from three questions in the HBSC questionnaire. The higher the score, the greater the engagement with school.

$\ddagger$ Two questions on attitudes to healthy eating were included in the student survey. There was some concern that as school approaches may influence attitudes to healthy eating these would be school-level variables rather than student-level ones. Low ICC scores indicated that these were not school-level variables.

where the lunch break was shorter. These findings may also be a reflection of the types of food schools are able to provide and that students can consume in shorter lunch breaks. Many unhealthy foods are quick to produce and serve and have high profit margins, maximising service and profits in a short lunch break ${ }^{(33)}$. No study was found that had used multilevel modelling to investigate the association between length of lunch break and student dietary choice while controlling for confounders at the student and school levels. Previous studies that have used a multilevel approach to investigate the impact of school on the food choices students make have incorporated few school-level factors that targeted student dietary choice in their analyses. They either focused on a very small number of factors such as the availability of unhealthy snacks and drinks ${ }^{(11,13,14)}$, the availability of healthy food ${ }^{(13)}$, the distance from school to the nearest food store ${ }^{(14)}$ and whether students were allowed to leave school grounds during lunch ${ }^{(11)}$, or considered general school-level characteristics that are not directly related to dietary choice ${ }^{(12)}$. However, a recent paper did find a significant association between the number of actions to promote healthy eating schools had in place and fruit and vegetable consumption by students ${ }^{(15)}$.

The significant associations found between the length of time schools allow for lunch and three of the dependent 
Table 3 School-level variables against percentage of schools by modal response of staff; secondary schools in Wales that were part of the 2005/2006 Health Behaviour in School-aged Children (HBSC) study

\begin{tabular}{|c|c|c|c|c|}
\hline Variable type & School-level variable & $\%$ & School-level variable & $\%$ \\
\hline \multirow{7}{*}{$\begin{array}{l}\text { Fixed school } \\
\text { characteristics }\end{array}$} & \multicolumn{2}{|l|}{ School type* $(n 64)$} & \multicolumn{2}{|c|}{ Shop close to school ( $n 64)$} \\
\hline & State & $92 \cdot 2$ & Yes & 53.1 \\
\hline & Independent & $7 \cdot 8$ & No & 46.9 \\
\hline & \multicolumn{2}{|c|}{ No. of pupils in school ${ }^{*}(n 64)$} & \multicolumn{2}{|c|}{$\%$ of pupils eligible for free school meals* $(n 64)$} \\
\hline & Minimum & 152 & Minimum & 0.0 \\
\hline & Maximum & 2045 & Maximum & $40 \cdot 9$ \\
\hline & Mean & 922 & Mean & $15 \cdot 8$ \\
\hline \multirow{24}{*}{$\begin{array}{l}\text { Healthy-eating- } \\
\text { promoting actions }\end{array}$} & \multicolumn{2}{|c|}{ Healthiness of school food complements education ( $n$ 64) } & \multicolumn{2}{|c|}{ No. of subjects healthy eating taught in $(n 64)$} \\
\hline & No & 59.4 & 2 subjects & 4.7 \\
\hline & Indistinct mode & 4.7 & 3 subjects & 29.7 \\
\hline & Yes & 35.9 & 4 subjects & $65 \cdot 6$ \\
\hline & \multicolumn{2}{|c|}{ Whole-school campaigns on healthy eating ( $n$ 64) } & \multicolumn{2}{|c|}{ Free samples of healthy food $(n 64)$} \\
\hline & No & 62.5 & No & 93.8 \\
\hline & Yes & 37.5 & Yes & 6.3 \\
\hline & \multicolumn{2}{|c|}{ Links to community healthy eating initiatives ( $n 64)$} & \multicolumn{2}{|c|}{ Quality of information provided on health eating ( $n$ 64 } \\
\hline & No & 87.5 & Not good & 60.9 \\
\hline & Yes & 12.5 & Good & $39 \cdot 1$ \\
\hline & \multicolumn{4}{|c|}{ Healthy eating policy $(n 64)$} \\
\hline & No policy known & $18 \cdot 8$ & & \\
\hline & Informal policy & $25 \cdot 0$ & & \\
\hline & Written policy & $56 \cdot 3$ & & \\
\hline & \multicolumn{2}{|c|}{ School has a SNAG $(n 64)$} & \multicolumn{2}{|c|}{ Snack vending in school ( $n$ 64) } \\
\hline & No & $85 \cdot 9$ & Yes & $53 \cdot 1$ \\
\hline & Yes & $14 \cdot 1$ & No & $46 \cdot 9$ \\
\hline & \multicolumn{2}{|c|}{ No. of Years allowed off premises for lunch $(n 64)$} & \multicolumn{2}{|c|}{ School in WNHSS† ( $n$ 64) } \\
\hline & 0 Years & 15.9 & Not in WNHSS & $34 \cdot 3$ \\
\hline & 1 Year & 7.9 & Phases $0-1$ & 21.4 \\
\hline & 2 Years & 9.5 & Phases 2-3 & 38.6 \\
\hline & 3 Years & $12 \cdot 7$ & Phases 4 or more & 5.7 \\
\hline & 4 Years & 1.6 & & \\
\hline & 5 Years & 52.4 & & \\
\hline
\end{tabular}

SNAG, School Nutrition Action Group; WNHSS, Welsh Network of Healthy School Schemes.

*School type, number of pupils on the school roll for Years 7-11 and percentage of pupils eligible for free school meals are fixed school characteristics that are not a part of a whole-school approach to healthy eating. These characteristics may impact on health behaviours and were used in the sampling frame for the HBSC study. Data concerning these were obtained from the Welsh Assembly Government. Shop close to the school from which pupils can buy food is also a fixed school characteristic that schools cannot influence. This was controlled for in the analysis, data for this variable came from the school staff postal surveys. †All of the healthy-eating-promoting action variables used in calculating the number of actions variable came from the school staff postal survey except the variables on school activity in the WNHSS, which came from information supplied by the Welsh Assembly Government.

Table 4 Dependent variables cross-tabulated against mean of school lunch-break length; secondary schools in Wales that were part of the 2005/2006 Health Behaviour in School-aged Children (HBSC) study

\begin{tabular}{|c|c|c|c|c|c|}
\hline & \multicolumn{3}{|c|}{ Percentage of students reporting to } & \multicolumn{2}{|c|}{ Mean student score } \\
\hline & $\begin{array}{l}\text { Eat fruit for } \\
\text { lunch }\end{array}$ & $\begin{array}{l}\text { Eat chips for } \\
\text { lunch }\end{array}$ & $\begin{array}{l}\text { Eat sweets for } \\
\text { lunch }\end{array}$ & $\begin{array}{l}\text { Fruit and vegetables } \\
\text { daily }\end{array}$ & $\begin{array}{l}\text { Unhealthy foods } \\
\text { daily }\end{array}$ \\
\hline \multicolumn{6}{|l|}{ Length of lunch break } \\
\hline Less than the mean & $46 \cdot 3$ & $28 \cdot 8$ & 38.8 & 0.55 & 1.04 \\
\hline $\begin{array}{l}\text { Equal to or greater than the } \\
\text { mean }\end{array}$ & 54.5 & $23 \cdot 9$ & $35 \cdot 2$ & 0.77 & 0.72 \\
\hline
\end{tabular}

Table 5 Odds ratios with $95 \%$ confidence intervals for dependent variables against length of lunch break from multilevel models controlling for student-level and school-level independent variables; secondary schools in Wales that were part of the 2005/2006 Health Behaviour in School-aged Children (HBSC) study

\begin{tabular}{lccccc}
\hline & \multicolumn{4}{c}{ Dependent variable } \\
\cline { 2 - 6 } & $\begin{array}{c}\text { Eat fruit for } \\
\text { lunch }\end{array}$ & $\begin{array}{c}\text { Eat chips for } \\
\text { lunch }\end{array}$ & $\begin{array}{c}\text { Eat sweets for } \\
\text { lunch }\end{array}$ & $\begin{array}{c}\text { Fruit and vegetables } \\
\text { daily }\end{array}$ & $\begin{array}{c}\text { Unhealthy foods } \\
\text { daily }\end{array}$ \\
\hline OR for lunch-break length & $2 \cdot 20$ & 0.98 & 0.56 & $2 \cdot 15$ & 0.44 \\
$95 \% \mathrm{Cl}$ & $1 \cdot 18,4 \cdot 11$ & $0.41,2 \cdot 32$ & $0.78,2.90$ & $1.33,3.47$ & $0.24,0.80$ \\
No. of students & 4998 & 4990 & 4989 & 4957 & 640 \\
No. of schools & 64 & 64 & 64 & 64 & 64 \\
\hline
\end{tabular}


variables in the present study highlight lunch-break length as an area schools should consider in encouraging healthy eating. The findings suggest that shorter lunch breaks discourage the consumption of fruit and vegetables by students. This should encourage schools to retain longer lunch breaks where possible and support this with other actions from the whole-school approach to healthy eating. Although no significant result was obtained with dependent variables measuring students eating chips or sweets for lunch, these were foods commonly eaten both inside and outside school when the present study was completed. Since the conclusion of the study new nutritional guidelines have been introduced into schools in England $^{(45)}$ and Wales ${ }^{(30)}$ which means these unhealthy foods should not be available to students on the school grounds. As students report that shorter breaks mean they are more likely to leave the school grounds to buy lunch ${ }^{(28-30,33)}$, these changes may support further the link between short lunch breaks and unhealthy dietary choice. Additionally, the healthiness of food available in the school was controlled for in analysis through a variable measuring the healthiness of school food as judged by staff along with variables on the presence of snack vending and the provision of free fruit. This should encourage policy makers to consider not just the food served in the school, but also the rules and regulations, along with the school environment, when considering dietary choice in the school. A followup investigation into the length of lunch break with these nutritional guidelines in place would benefit our understanding of the impact it has on student dietary choice.

School reasons for changing the length of lunch break and the impact of the amount of time schools allow for lunch on student lunch behaviour should be investigated further, such that schools can consider the impact on the dietary choice of students when reviewing the length of lunch break for other reasons. A longitudinal study including schools that change the length of lunch break would allow causality to be investigated. Future studies should also collect data from the caterers who can provide insight into the preparation and serving of foods over the lunch break.

The findings from the current paper indicate that schools should consider the impact lunch-break length has on student dietary choice as well as on other behaviours, and view it as an important component of a whole-school approach to health eating. A shortening of the amount of time allowed for lunch should be discouraged and policy makers and those involved in the provision of food should work with schools in maintaining lunch breaks of a length that allow pupils to make healthy choices and support the nutritional guidelines schools now follow.

\section{Acknowledgements}

Acknowledgements: The data in the present paper came from the author's $\mathrm{PhD}$ work undertaken at Cardiff
University that was supervised by Professor Laurence Moore, now Director of the Medical Research Council (MRC) Social and Public Health Sciences Unit, Glasgow, and Professor Simon Murphy of the Centre for the Development and Evaluation of Complex Interventions for Public Health Improvement (DECIPHer). HBSC is an international study carried out in collaboration with the WHO Regional Office for Europe. The International Coordinator of the study is C. Currie, University of Edinburgh, UK and the Data Bank Manager is O. Samdal, University of Bergen, Norway. Within Wales, the HBSC study is coordinated by the Health and Social Services team within the Social Research and Information Division of the Welsh Government, led by C. Roberts. For details, see http://www.hbsc.org. Financial support: This work was supported by the MRC, UK as part of the author's $\mathrm{PhD}$; the author's current position at the University of Oxford is funded by the British Heart Foundation (BHF). The MRC and the BHF had no role in the design, analysis or writing of this article. Conflict of interest: None. Authorship: N.T. completed the data collection, analysis and writing of the paper. Ethics of buman subject participation: Ethics approval was provided by the Cardiff University Social Science Research Ethics Committee before commencement of data collection.

\section{References}

1. Craig R \& Mindell J (2008) The Health Survey for England 2006: CVD and Risk Factors Adults, Obesity and Risk Factors Children. Leeds: Health \& Social Care Information Centre.

2. Wang Y \& Lobstein T (2006) Worldwide trends in childhood overweight and obesity. Int J Pediatr Obes 1, 11-15.

3. Ridler C, Dinsdale H \& Rutter H (2013) National Child Measurement Programme: Changes in Children's Body Mass Index Between 2006/07 and 2011/12. Oxford: National Obesity Observatory.

4. Townsend N \& Scriven A (2014) Public Health Mini-Guides: Obesity. London: Churchill Livingstone/Elsevier.

5. Townsend N, Bhatnagar P, Wickramasinghe K et al. (2013) Children and Young People Statistics 2013. London: British Heart Foundation.

6. Stamatakis E, Zaninotto P, Falaschetti E et al. (2010) Time trends in childhood and adolescent obesity in England from 1995 to 2007 and projections of prevalence to 2015 . J Epidemiol Community Health 64, 167-174.

7. Story M, Kaphingst KM \& French S (2006) The role of schools in obesity prevention. Future Child 16, 109-142.

8. Nelson M, Bradbury J, Poulter J et al. (2004) School Meals in Secondary Schools in England. London: King's College London, National Centre for Social Research, Nutrition works!.

9. Ball K, Timperio A \& Crawford D (2006) Understanding environmental influences on nutrition and physical activity behaviors: where should we look and what should we count? Int J Behav Nutr Phy Act 3, 33.

10. Dimbley H \& Vincent J (2013) The School Food Plan.http:// www.schoolfoodplan.com/wp-content/uploads/2013/07/ School_Food_Plan_2013.pdf (accessed February 2014).

11. Maes L \& Lievens J (2003) Can the school make a difference? A multilevel analysis of adolescent risk and health behaviour. Soc Sci Med 56, 517-529. 
12. West P, Sweeting H \& Leyland A (2004) School effects on pupils' health behaviours: evidence in support of the health promoting school. Res Papers Educ 19, 261-291.

13. Krolner R, Due P, Rasmussen M et al. (2009) Does school environment affect 11-year-olds' fruit and vegetable intake in Denmark? Soc Sci Med 68, 1416-1424.

14. Van der Horst K, Timperio A, Crawford D et al. (2008) The school food environment: associations with adolescent soft drink and snack consumption. Am J Prev Med 35, 217-223.

15. Townsend N, Murphy S \& Moore L (2011) The more schools do to promote healthy eating, the healthier the dietary choices by students. J Epidemiol Community Health 65, 889-895.

16. De Bourdeaudhuij I, Van Cauwenberghe E, Spittaels $\mathrm{H}$ et al. (2011) School-based interventions promoting both physical activity and healthy eating in Europe: a systematic review within the HOPE project. Obes Rev 12, 205-216.

17. Knai C, Pomerleau J, Lock K et al. (2006) Getting children to eat more fruit and vegetables: a systematic review. Prev Med 42, 85-95.

18. Summerbell CD, Waters E, Edmunds L et al. (2005) Interventions for preventing obesity in children. Cochrane Database Syst Rev issue 3, CD001871.

19. Thomas H (2006) Obesity prevention programs for children and youth: why are their results so modest? Health Educ Res 21, 783-795.

20. Dooris M (2009) Holistic and sustainable health improvement: the contribution of the settings-based approach to health promotion. Perspect Public Health 129, 29-36.

21. World Health Organization (1986) Ottawa Charter for Health Promotion. Geneva: WHO.

22. Scottish Executive (2007) Schools (Health Promotion and Nutrition) Scotland Act Health Promotion Guidance for Local Authorities and Schools. Edinburgh: The Stationery Office.

23. National Health Services, National Services Scotland (2010) Scottish Primary School Children. Child Health Systems Programme - School. http://www.isdscotland.org/isd/3640. html (accessed April 2014).

24. Department of Education Northern Ireland (2008) New Nutritional Standards for School Lunches and Other Food in Schools. Belfast: DENI.

25. National Institute for Health and Clinical Excellence (2006) Obesity: Guidance on the Prevention, Identification, Assessment and Management of Overweight and Obesity in Adults and Children (CG 43). London: NICE; available at http://www.nice.org.uk/

26. Welsh Assembly Government (2007) Developing a Whole School Food and Fitness Policy. Cardiff: Welsh Assembly Government, Public Health Improvement Division.

27. World Health Organization (2009) Interventions on Diet and Physical Activity: What Works. Geneva: WHO.

28. Ofsted (2006) Healthy Eating in Schools. London: Ofsted Communications Team.
29. Ofsted (2007) Food in Schools: Encouraging Healthier Eating. London: Ofsted Communications Team.

30. Welsh Assembly Government (2007) Appetite for Life Action Plan. Cardiff: Welsh Assembly Government, Public Health Improvement Division.

31. Nicholas J, Powell R \& Smith R (2006) Review of the School Meals Service and Other School Nutritional Issues in Wales. Slough: National Foundation for Educational Research.

32. Harper C, Wood L \& Mitchell C (2008) The Provision of School Food in 18 Countries. Sheffield: School Food Trust.

33. Estyn (2008) Food and Fitness in Schools. Cardiff: Her Majesty's Inspectorate for Education and Training in Wales.

34. Evans CEL, Greenwood DC, Thomas JD et al. (2010) A cross-sectional survey of children's packed lunches in the UK: food- and nutrient-based results. J Epidemiol Community Health 64, 977-983.

35. Nicholas J, Wood L, Harper C et al. (2013) The impact of the food-based and nutrient-based standards on lunchtime food and drink provision and consumption in secondary schools in England. Public Health Nutr 16, 1052-1065.

36. Currie C, Zanotti C, Morgan A et al. (2012) Social Determinants of Health and Well-Being among Young People. Health Behaviour in School-aged Children (HBSC) Study: International Report from the 2009/2010 Survey. Copenhagen: WHO Regional Office for Europe.

37. Townsend N \& Foster C (2013) Developing and applying a socio-ecological model to the promotion of healthy eating in the school. Public Health Nutr 16, 1101-1108.

38. Currie C, Gabhainn S, Godeau E et al. (2008) Inequalities in Young People's Health. HBSC International Report from the 2005/2006 Survey. Edinburgh: Child and Adolescent Health Research Unit (CAHRU).

39. Currie C, Samdal O, Boyce W et al. (2002) Research Protocol for the 2001/2002 Survey. Edinburgh: HBSC.

40. Dennison CM \& Shepherd R (1995) Adolescent food choice: an application of the Theory of Planned Behaviour. J Hum Nutr Diet 8, 9-23.

41. Bowker S, Crosswaite C, Hickman M et al. (1998) The healthy option - a review of activity on food and nutrition by UK schools involved in the European Network of Health Promoting Schools. Health Educ 98, 135-141.

42. Bell M (2008) Food and Fitness Implementation Plan: Promoting Healthy Eating and Physical Activity for Children and Young People in Wales. http://wales.gov.uk/publications/ accessinfo/drnewhomepage/healthdrs/Healthdrs2008/promote helthyeatingincyp/?lang=en (accessed September 2011).

43. Bowker S \& Tudor-Smith C (2000) The health-promoting school in Wales: an overview. Health Educ 100, 154-160.

44. Roberts C, Freeman J, Samdal O et al. (2009) The Health Behaviour in School-aged Children (HBSC) study: methodological developments and current tensions. Int J Public Health 54, Suppl. 2, 140-150.

45. School Food Trust (2007) A Guide to Introducing the Government's New Food-Based Standards for all School Food Other than Lunches. Sheffield: School Foods Trust. 